\title{
The term "asthma" should be avoided in describing the chronic pulmonary disease of prematurity
}

To the Editor:

We read with interest the report from KäLLÉn et al. [1] that preterm birth and (to a lesser extent) restricted intrauterine growth both substantially increase the risk of developing "childhood asthma". Their data are interesting, and several plausible hypotheses are advanced to explain the correlation between prematurity (and intrauterine growth restriction) and the development of asthma later on.

As in numerous other studies [2-4], cases of asthma were identified on the strength of anti-asthma drug prescriptions. Rightly enough, a persistent use of anti-asthma drugs (at least five prescriptions) was required to minimise the inclusion of non-asthmatic cases [1]. We nonetheless have the feeling that the results of the study essentially confirm the well-known circumstance that preterm-born individuals frequently have chronic/recurrent broncho-obstructive symptoms throughout their childhood (at least), and are often treated with the same drugs as asthma patients. However, chronic lung disease following premature birth in the long term may differ substantially from asthma in several ways, and, although anti-asthma drugs are commonly prescribed, they have yet to be proved effective in these patients.

Asthma and chronic lung disease after premature birth share some clinical and physiological features, but not the same underlying mechanisms. For example, the typical eosinophil-mediated inflammation of bronchial asthma is negligible in survivors of premature birth or bronchopulmonary dysplasia (BPD), given the normal exhaled nitric oxide levels found in these subjects [5]. As KäLléN et al. [1] rightly mentioned, moreover, atopy is not as common in children born preterm as it is in children with asthma [6]. Bronchial obstruction after preterm birth probably stems from specific mechanisms relating to an abnormal course of lung development early in life [7]. Indeed, exposure to harmful factors in the early stages of lung morphogenesis may prevent a normal pulmonary architecture from developing, with potentially life-long consequences [8].

Given the structural nature of their broncho-obstructive disease, it is hardly surprising that survivors of prematurity and BPD (unlike asthmatics) have only a partial response to inhaled $\beta_{2}$-agonists. A reduction in the supporting parenchymal tissue within the lung can result in collapse of the small conductive airways during expiration. Notably, morphological studies using high-resolution computed tomography indicate that adolescent and young adult survivors of BPD have lung changes more closely resembling those of pulmonary emphysema than those seen in asthma [9]. Such an early-onset emphysema may have worrying prognostic implications, and there is concern that the broncho-obstructive disorder following premature birth may progress, in the more severe cases, to a chronic obstructive pulmonary disease (COPD)-like phenotype. Unfortunately, virtually nothing is known about the lung pathology of survivors of BPD beyond infancy, and the link between BPD and asthma cannot be demonstrated [8].

Given these considerations, the respiratory symptoms that may follow premature birth and persist through childhood and into adult age should not be labelled as asthma: this may not be pathophysiologically accurate and could promote these subjects' chronic use of asthma treatments, such as inhaled corticosteroids, which may well be ineffective or even unsafe [10].

We suggest that the term "asthma" should be avoided when dealing with ex-preterm and BPD subjects, and substituted with the term "chronic obstructive pulmonary disease of prematurity".

@ERSpublications

The term "asthma" should be avoided when dealing with ex-preterm and bronchopulmonary dysplasia subjects http://ow.ly/nLYlY

Marco Filippone, Silvia Carraro and Eugenio Baraldi

Women's and Child's Health Dept, University of Padova, Padova, Italy.

Correspondence: E. Baraldi, Unit of Pediatric Respiratory Medicine and Allergy, Women's and Child's Health Dept, University of Padova, Via Giustiniani 3, 35128 Padova, Italy. E-mail: baraldi@pediatria.unipd.it 


\section{References}

1 Källén B, Finnström O, Nygren KG, et al. Association between preterm birth and intrauterine growth retardation and child asthma. Eur Respir J 2013; 41: 671-676.

2 Crump C, Winkleby MA, Sundquist J, et al. Risk of asthma in young adults who were born preterm: a Swedish national cohort study. Pediatrics 2011; 127: e913-e920.

3 Vogt H, Lindstrom K, Braback L, et al. Preterm birth and inhaled corticosteroid use in 6- to 19-year-olds: a Swedish national cohort study. Pediatrics 2011; 127: 1052-1059.

4 Metsala J, Kilkkinen A, Kaila M, et al. Perinatal factors and the risk of asthma in childhood - a population-based register study in Finland. Am J Epidemiol 2008; 168: 170-178.

5 Baraldi E, Bonetto G, Zacchello F, et al. Low exhaled nitric oxide in school-age children with bronchopulmonary dysplasia and airflow limitation. Am J Respir Crit Care Med 2005; 171: 68-72.

6 Siltanen M, Wehkalampi K, Hovi P, et al. Preterm birth reduces the incidence of atopy in adulthood. J Allergy Clin Immunol 2011; 127: 935-942.

Jobe AJ. The new BPD: an arrest of lung development. Pediatr Res 1999; 46: 641-643.

Baraldi E, Filippone M. Chronic lung disease after premature birth. N Engl J Med 2007; 357: 1946-1955.

Wong PM, Lees AN, Louw J, et al. Emphysema in young adult survivors of moderate-to-severe bronchopulmonary dysplasia. Eur Respir J 2008; 32: 321-328.

10 Pantalitschka T, Poets CF. Inhaled drugs for the prevention and treatment of bronchopulmonary dysplasia. Pediatr Pulmonol 2006; 41: 703-708.

Eur Respir J 2013; 42: 1430-1431 | DOI: 10.1183/09031936.00055913 | Copyright @ERS 2013

From the authors:

M. Filippone et al. stress in their correspondence that infants born preterm may develop recurrent bronchoobstructive symptoms, which they want to call "chronic obstructive pulmonary disease of prematurity", a term that may be useful in clinical practice but is difficult to apply in epidemiological studies as it is not defined by standard coding (International Classification of Diseases (ICD), 10th revision). Perhaps this will change in later ICD revisions. The presence of such cases will of course not prevent the fact that asthma can develop in a premature child and may do so more often than in term infants. In our study [1], we saw an increased use of anti-asthmatic drugs (after the age of 2 years) in children born in weeks 35-38 (table 1) or with birth weights 1500-2999 g (table 2). The effect of intrauterine growth retardation was visible even among children born in weeks 39-41 (table 3). Only 39 out of the 43387 "asthmatic" children had a neonatal diagnosis of bronchopulmonary dysplasia (table 4). The reference by PANTALiTSCHKA and PoETs [2] that is cited by M. Filippone et al. refers to treatment of the neonate with bronchopulmonary dysplasia and is not relevant for the treatment after age 2 years that we used for case definition in our study. drugs http://ow.ly/nLYqN

Orvar Finnström $^{1}$ and Bengt Källén ${ }^{2}$

${ }^{1}$ Dept of Paediatrics, Linköping University Hospital, Linköping, and ${ }^{2}$ Tornblad Institute, University of Lund, Lund, Sweden.

Correspondence: B. Källén, Tornblad Institute, Biskopsgatan 7, SE-223 62 Lund, Sweden. E-mail: Bengt.Kallen@med.lu.se

Received: April 162013 | Accepted: April 192013

Conflict of interest: None declared.

\section{References}

1 Källén B, Finnström O, Nygren KG, et al. Association between preterm birth and intrauterine growth retardation and child asthma. Eur Respir J 2013; 41: 671-676.

2 Pantalitschka T, Poets CF. Inhaled drugs for the prevention and treatment of bronchopulmonary dysplasia. Pediatr Pulmonol 2006; 41: 703-708. 